existence, around and up to which the earliest glacial marine accumulations of sand and shingle were bedded, and which, as subsequent southerly and westerly subsidence ingulphed all but the highest downs of the south of England, eventually spread over these islands, yet I did not connect this first movement with the pressure of the land ice. I have since, however, perceived that this connection exists; for, as the Glacial period came on, the precipitation must necessarily, on account of latitude, have taken more exclusively the form of snow in Scotland before it did so in Cumberland and Wales; and, by thus accumulating land ice earlier in Scotland, caused this northerly subsidence. As the cold increased the precipitation in the form of snow reached its maximum in Westmoreland and Cumberland, and yet later somewhat in Wales; and as it did so, the pressure of the land ice engendered by it turned the depression increasingly in those directions, so that eventually all England, save the highest downs, and even the lower ends of the river valleys of NorthWestern France became submerged proportionately to their contiguity to the foci of pressure. These increments of depression I have in this memoir traced by more than one train of evidence, and shown how this change of inclination, by diverting the directions taken by the land ice to the sea, changed also the character of the materials of which the resulting morainic clay is made up, and so gave rise to those Upper and Lower clays of the major glaciation in Yorkshire, which have been seized upon to support the hypothesis of alternations of climate ditring that glaciation.

The connection between the augmenting weight of the land ice and subsidence seems to me so clear, that I cannot but think that American geologists have fallen into an error, in regarding the Champlain period as belonging to the wane of the great glaciation, instead of to its culmination. It seems to me that although the increasing volume of the land ice in the Lake (or St. Lawrence) basin caused this ice at its western extremity, where the parting between the two basins is very low, to invade the upper part of the great Mississippi basin, yet its weight where thickest - that is to say, towards its eastern extremity, which was that of greatest snow precipitation-so pressed this extremity down that the seaward termination of this ice in the Gulf of St. Lawrence retreated before the greater depth of sea there which thus resulted, and so allowed the sea to penetrate to Montreal and Lake Champlain, near the former of which places the remains of its inhabitants have been left at an elevation of abont 600 feet.

With all this, however, we must not be led into regarding all movements of subsidence as a result of increasing accumulations, whether of sediment or otherwise; for such is evidently not the case, though to instance this would lead me beyond the object of this letter.

Martlesham, near Woodbridge, October II

THE above remarks require but little conment, and chiefly tend to show that Mr. S. V. Wood attaches increased importance to the idea that weight produces subsidence. He speaks of elevation commencing before the retreat of the glaciers, but that they would be enormously lightened before retreating is a fact that I can hardly suppose he has overlooked. In ascending the Jungfrau many years ago, when the Swiss glaciers were diminishing, I crossed from the Grindel wald on to the Aletsch, and had to descend a cliff of nearly vertical ice, which my recollection tells me was some sixty feet high, in order to pass from one to the other. The difference in level was caused by the extra rapid melting of the Aletsch, owing to its more southern aspect and exposure to the Föhn wind. This was at the head of the glacier, and the melting was much more rapid lower down, though the superficial area had not contracted to any appreciable extent. This loss of weight would lead to elevation long before the disappearance of the ice. J. STARKIE GARDNER

\section{Snake Bite}

I WAS an eye-witness to the following:-My brother was walking within a field of the Land's End when he stooped to pick up a large snalie, apparently nearly a yard long, which bit him on the thumb. The bite became very painful in a few moments, and we realised for the first time that it was poisoned. In less than five minutes he was in the hotel and swallowed half a pint of neat brandy, and soon after some ammonia and water, without any effect. The wound had been well sucked and was steeped in ammonia, bat the arm szon swelled to the size of the body, and the swelling began to extend down the ribs. The thumb was lanced while immersed in hot water, and the result was similar to the first gashes in a shoulder of mutton, the ex. posed flesh being dark mulberry colour, and not a drop of blood flowing. He recovered in seven or eight days, but was weak for some time.

Park House, St. John's Wood Park, N.W.

\section{The Observation of Meteors}

ACCOUNTS of large meteors form a frequent subject of correspondence in the columns of scientific journals, but it is not often the case that the descriptions of these phenomena are sufficiently exact to be valuable for purposes of calculation. Rough estimates of the direction and position of flight are of little utility, and the vague statements often made occasion an endless source of difficulty in the satisfactory reciuction of results. It is true that observers of fireballs are generally taken unawares by the suddenness of the apparitions, and that the visible paths are seldom to be noted accurately. Before the observer collects himiself to record the facts of the display it has disappeared, and he has to rely solely npon the impressions retained in his memory.

But, notwithstanding this drawback, the observations of large meteors as published from time to time would possess far greater scientific value if observers would attend more scrupulously to that most essential detail, the diriction of fight, and express it by some method of uniformity. Sometimes we find the path vaguely stated as being from "east to south," without any attempt to estimate the altitude of the bejinning and end point of the course. On other occasions a meteor is described as passing above or below certain stars or planets. The latter method, though an improvement upon the former, is to some extent indefinite, and therefore unsatisfactory, as giving unnecessary trouble to those who undertake the reduction of such materials. For instance, a meteor is observed early in August, 188I, shoot ing from "some distance below Saturn towards Comet B." Now in reducing this account troublesome references have to be made to find the places of the two objects on the dates men tioned, and then we are left to guess at the "distance below Saturn" implied in the description. These objections would disappear, and the comparison of observations be greatly facilitated, could observers be induced to give the right ascension and declination of the beginning and end points of the visible paths. These elements admit of ready determination by projecting the objerved flights upon a star chart or celestial globe and reading them off. Even in cases where the observations are uncertain, the observer should fix the fath according to this method as nearly as possible, for it is manifest that it is infinitely preferable to the vague and often worthless attempts to guess altitudes, compass bearings, \&c., and, moreover, it renders the after comparison of observations a work of greater facility and precision.

Though the direction of flight is the all-important element to be determined by meteor observers, there are some minor points which should also be carefully recorded. The time of appearance, brightness, approximate duration, and whether accompanied by phosphoric streaks or spark trains, are each important in their way, and must be stated whenever feasible. If this were done more systematically, the observations of fireballs would acquire additional value, and may quite possibly develop some new facts either as to their appearance or origin.

Bristol, October 22

W. F. DENNING

\section{"Partials"}

IT is a well known fact that no muical sound is produced alone, but the instant it is sounded a series of other sounds springs from it, and always in a certain order and ratio. Next to the primary tone, the octave is heard, then the octave fifth, the double octave, the double octave third, the donble cctave fifth, the extra fiat double octave seventh, the treble octave, and so on. The origin of these "partials" bas long been an interesting study, and a solution has occurred to me which I think is the true one.

We have the fact that an object seen by the eye for ever so short a time leaves its impression on the optic nerves about the eighth of a second after it has fassed away". By analogy it seems highly probab? tbat all our nerves, including those of the 